\title{
EDITORIAL
}

\section{Publicar a Educar em Revista em meio a tantos solavancos e retrocessos}

\author{
Gizele de Souza* \\ Catarina Moro*
}

Depois de tantos meses e um longo período de pandemia no mundo, imaginávamos que o editorial de 2021 pudesse assumir outra perspectiva, mais alentadora e esperançosa. De certo modo, chegamos ao final deste ano com prospectiva positiva de uma moderada transição de tempos de isolamento para novas práticas de convívio social, devido ao avanço no processo de vacinação contra a Covid19. Entretanto, no Brasil, as dificuldades não se referem apenas à dimensão sanitária (o que já seria grave o suficiente), mas têm relação com aspectos da vida política, econômica, cultural, educativa e também acadêmica. Em poucas linhas, não será possível aqui sintetizar, tantos retrocessos sofridos por nós brasileiros, mas destacar alguns temas que nos afetam diretamente na condição de um periódico educacional.

Desde 2016 acompanhamos, com preocupação, a adoção de cortes federais e restrições orçamentárias para a ciência e tecnologia. No editorial do ano passado, já indicávamos sobre o agravamento destas restrições, como por exemplo, a não obtenção de apoio financeiro (em 2019) para as revistas das Humanidades (aqui incluídas as de educação) pelas principais agências de fomento, como do Conselho Nacional de Desenvolvimento Científico e Tecnológico $(\mathrm{CNPq})^{1}$. Em 2020 nenhum apoio federal foi disponibilizado, e em 2021 um novo edital de fomento foi publicado, submetemos proposta a ele, mas aguardamos o resultado com apreensão, menos em relação às possiblidades de

1 Segundo edital de fomento N.19/2019 Programa Editorial, a Educar em Revista, assim como outras revistas da educação e humanidades, foi avaliada favoravelmente, mas não foi contemplada com recursos financeiros.

* Universidade Federal do Paraná. Setor de Educação. Programa de Pós-Graduação em Educação. Núcleo de Estudos e Pesquisas em Infância e Educação Infantil (NEPIE). Curitiba, Paraná, Brasil. E-mail: gizelesouza@ufpr.br - https://orcid.org/0000-0002-6487-4300 - E-mail: catarina.moro@ufpr.br - https://orcid.org/0000-0003-3109-5885 
atendimento às exigências acadêmicas - posto que a Educar em Revista mantém compatível avaliação nacional em requisitos estipulados para um periódico qualificado como QualisA1 - mas, muito mais, em virtude dos recentes e maiores cortes para a ciência e tecnologia neste ano corrente, como assevera Escobar.

A ciência brasileira terá que sobreviver em 2021 com um orçamento pífio. O Ministério da Ciência, Tecnologia e Inovações (MCTI) foi o que sofreu o maior corte no orçamento federal aprovado em 25 de março pelo Congresso Nacional, com uma redução de $29 \%$ dos seus recursos, em comparação com 2020. O orçamento de fomento do Conselho Nacional de Desenvolvimento Científico e Tecnológico (CNPq) - que é vinculado ao MCTI - será de apenas R \$ 23,7 milhões; uma quantia absolutamente irrisória para a sustentação da produção científica nacional (ESCOBAR, 2021).

Mas, é enganoso pensarmos que nada pode piorar mais quando ruim já está. Entretanto, em outubro de 2021, novos cortes foram realizados no orçamento do Ministério da Ciência, Tecnologia e Inovações (MCTI), "a pedido do Ministério da Economia, parlamentares reduzem orçamento suplementar da área para R\$ 89,7 milhões, comprometendo o custeio de bolsas e projetos de pesquisa" (ANDRADE, 2021). Segundo a avaliação deste artigo da Revista da FAPESP, após o Congresso Nacional aprovar o Projeto de Lei que reduz drasticamente o valor previsto ao órgão, “a pasta receberia R \$ 690 milhões, mas agora poderá contar com apenas R \$ 89,7 milhões" (ANDRADE, 2021).

As apreensões se ampliam também para outros setores, como o das políticas da Coordenação de Aperfeiçoamento de Pessoal de Nível Superior (Capes) em relação aos processos de avaliação da pós-graduação e dos periódicos. Desde 2020, acompanhamos os debates e embates em relação às decisões de avaliação de periódicos do Colégio de Humanidades no Conselho TécnicoCientífico da Educação Superior (CTC-ES). Foram muitas as tentativas e estratégias dos representantes das áreas deste Colegiado, inclui-se aqui a forte e competente atuação dos representantes da área de educação, para minimizar ou negociar propostas para o Qualis Periódicos que reduzissem possíveis impactos negativos devido às proposições de cálculos com utilização dos indexadores CiteScore (Scopus) e fator de impacto (Journal Citation Reports - JCR/Web of Science). A área da educação, na Capes, optou por assumir a utilização do índice h5 (Google Scholar), como instrumento de avaliação do quesito de fator de impacto das revistas, separando-as em três grupos (periódicos em língua portuguesa, periódicos em língua inglesa e periódicos nas demais línguas), permitindo o cotejamento entre periódicos equivalentes, considerando que a 
língua de publicação do periódico é fator determinante, tanto no alcance, como na citação e impacto do periódico. Contudo, estes esforços parecem não ter sido suficientes para barrar o oportunismo e o rompimento do senso democrático das decisões assumidas pelo Colégio de Humanidades (CTS), diante das ações judiciais impetradas recentemente ${ }^{2}$, que colocaram em suspenção todo o processo avaliativo da pós-graduação brasileira iniciada há quase quatro anos.

A Educar em Revista, em consonância a outros periódicos da área, partilha junto ao Fórum de Editores de Periódicos da Área de Educação (FEPAE), da preocupação e defesa pela manutenção e estabilidade dos processos avaliativos, tanto voltados para a pós-graduação, como para os periódicos; também pela participação dos editores no diálogo destes processos avaliativos; e em relação ao emprego de índices de citação ou métricas, entendemos que estas devem compor junto a outros aspectos de qualificação dos periódicos.

As adversidades encontradas para o trabalho editorial também comparecem em âmbito local, institucional, com cortes de recursos e problemas de gestão, em especial, pela redução de profissionais de revisão e diagramação dos manuscritos, bem como no cumprimento dos prazos e ausência de apoio da universidade para este setor de periódicos. A revista continua a se manter, por compromisso dos colaboradores autores, pareceristas e consultores, pelo ofício da editoria e secretaria e apoio - incondicional - da gestão do Setor de Educação e do Programa de Pós-Graduação em Educação da UFPR.

Mas não só duras notícias são aqui partilhadas, este editorial traz como boas novas a manutenção - em fluxo contínuo - da publicação de manuscritos oriundos de demanda contínua, dossiês temáticos, entrevistas e documentos. Na seção dossiê temático, fruto do edital público de $2019^{3}$, tivemos o êxito em publicar 82 manuscritos em sete (7) dossiês. O primeiro intitulado " $A$ dimensão biográfica como processo de formação e compreensão de si e do mundo", contou com a organização de Maria Amália Almeida Cunha e Hervé Breton. O segundo "Corpo e História: os múltiplos processos de educação do corpo", com a coordenação de Andrea Moreno e Evelise Amgarten Quitzau; o terceiro "Bases Nacionais e o Ensino de História embates, desafios e possibilidades na/ entre a Educação Básica e a formação de professores", sob o trabalho de Nádia Gaiofatto Gonçalves e Ana Maria Ferreira da Costa Monteiro. O próximo voltouse ao tema da "Educação Ambiental e a Escola Básica: contextos e práticas", sob a batuta de Elaine Angelina Colagrandre e Luciana Aparecida Farias, tendo na sequência "Implementação de políticas públicas para o combate às

2 Ações apresentadas a pedido do Ministério Público Federal (MPF) do Rio de Janeiro.

3 Que previa dois formatos de dossiês - um, com chamada aberta para submissão de artigos; outro, com composição fechada contendo todos os manuscritos. 
desigualdades educacionais", com a coordenação de Naira Muylaert; "Desafios da avaliação na e da Educação Infantil", com Patrícia Corsino na organização e por fim "Criatividade, emoção e educação", sob a coordenação de Tânia Stoltz.

Na seção demanda contínua, foram 44 artigos. De entrevista, publicamos três textos e na seção documentos mais três manuscritos, sendo um deles no âmbito das comemorações do PPGE/UFPR "História e memória do Programa de Pós-Graduação em Educação da Universidade Federal do Paraná (19752020)", de responsabilidade de Marcus Levy Bencostta, Marília Andrade Torales Campos, Cláudio de Sá Machado Jr. Os demais textos se referem às comemorações do Centenário de Paulo Freire e contam com a contribuição do pesquisador italiano Massimiliano Fiorucci ${ }^{4}$ e dos brasileiros Sergio Haddad e Maria Clara di Piero, com base nas provocações, teorizações e práticas imprescindíveis e indeléveis desse pensador brasileiro, que tem marcado experiências e pesquisas mundialmente desde os anos de 1960 e que segue como patrono da educação brasileira (BRASIL, 2012), apesar dos acintes que sua memória vem recebendo em tempos de política obscura no Brasil.

Como se observa, a Educar em Revista, apesar de todas as dificuldades já mencionadas, vem mantendo o padrão de excelência nacional e internacional - publicou 132 manuscritos neste ano - e, ainda, atualizou (desde 2020) a identidade visual ${ }^{5}$ para os volumes das suas publicações anuais, conforme as imagens a seguir:

\section{IMAGENS 1 E 2 -CAPAS DAS EDIÇÕES ANUAIS DA EDUCAR EM REVISTA, 2020 E 2021.}
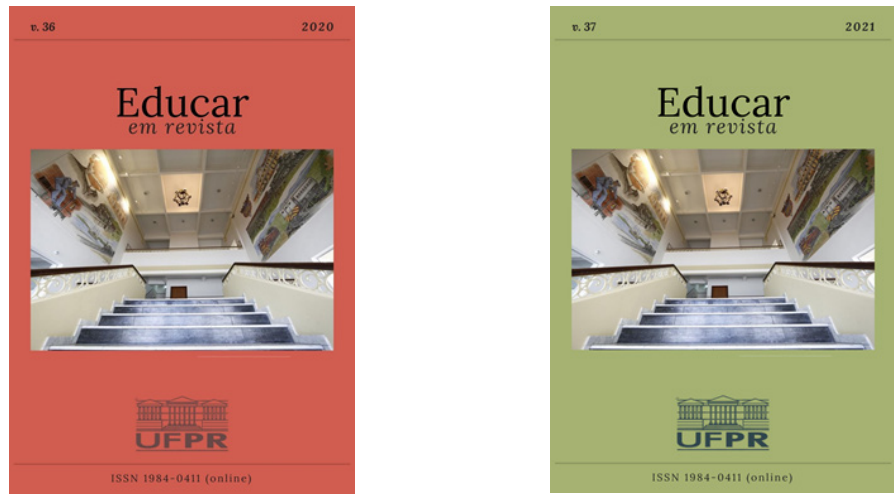

FONTE: Educar em Revista/UFPR.

4 Da Università degli Studi Roma Tre e presidente da SIPED (Società Italiana di Pedagogia).

$5 \mathrm{O}$ trabalho foi realizado pela pesquisadora Ana Luisa Manfredini Araújo, integrante do Núcleo de Estudos e Pesquisas em Infância e Educação Infantil (NEPIE/UFPR). 
A imagem que figura na capa das edições anuais da revista corresponde às escadarias do Campus Rebouças, local onde se situa as instalações da Educar em Revista, bem como de boa parte das unidades do Setor de Educação, especialmente a pós-graduação, gabinetes de professores e núcleos de pesquisa.

Entre solavancos e retrocessos do Brasil atual, "publicar" assumiu outros significados além da condição de verbo, que divulga e propaga artigos científicos, passou também a ser um feito, uma atitude de compromisso e coragem com a ciência, tão aviltada nesses tempos de gestão federal marcada por negacionismo, erros, descaso, violência e desprestígio. Dar conta de receber, selecionar, avaliar, revisar, diagramar, publicar e divulgar manuscritos científicos, corresponde a um trabalho que foi revestido de muitos outros desafios - além dos domínios técnicos próprios da tarefa editorial - foram necessárias ações políticas, econômicas e acadêmicas de insistência, negociação e colaboração entre pesquisadores, editores, gestores do Setor e do Programa de Pós-Graduação, e fundamentalmente sintonia interna da própria equipe editorial da Educar em Revista. Sem isso, seguramente sucumbiríamos! Mas cá estamos, atentas e fortes, ainda que tenhamos temido e continuemos temendo as consequências da ausência de políticas e decisões acertadas, diante de uma questão sanitária grave como a Covid -19, que até o encerramento do presente texto provocou mais de 608 mil mortes no Brasil.

Diante do exposto, uma referência mitológica nos toma a atenção - é a figura de Janus ou Jano, divindade romana, bifronte, simultaneamente atento ao passado e ao porvir, como um porteiro que atenta às transições e passagens, que guarda as entradas e saídas, que demarca os princípios, os inícios (CHEVALIER; GUEERBRANT, 1999) ${ }^{6}$. Seguimos certas da necessária transformação que, enquanto sociedade, precisamos conquistar. Como Janus nos cabe atentar tanto ao que transcorreu, no sentido de ter consciência do que foi e também do que poderia ter sido, mas não foi e do que não pôde ser, como ao que queremos viver no futuro e sobre ele escrever.

\section{REFERENCIAS}

ANDRADE, Rodrigo de Oliveira. Congresso promove novos cortes nos recursos para a ciência. Revista da FAPESP, São Paulo, 11 nov. 2021. Newsletter. Disponível em: https://

6 Alguns desses elementos são examinados por Chevalier e Gueerbrant no verbete "Jano", em Dicionário de Símbolos (1999). 
revistapesquisa.fapesp.br/congresso-promove-novos-cortes-nos-recursos-para-a-ciencia/. Acesso em: 02 nov. 2021.

CHEVALIER, Jean; GHEERBRANT, Alain. Dicionário de Símbolos: mitos, sonhos, costumes, gestos, formas, figuras, cores, números. 14. ed. Rio de Janeiro: José Olympio, 1999.

BRASIL. Lei no 12.612, 13 de abril de 2012. Declara o educador Paulo Freire Patrono da Educação Brasileira. Diário Oficial da União: seção 1, Brasília, DF, p. 1, 16 abr. 2012.

ESCOBAR, Herton. Orçamento 2021 compromete o futuro da ciência brasileira. Jornal da USP. São Paulo, 09 abr. 2021. Disponível em: https://jornal.usp.br/ciencias/orcamento2021-compromete-o-futuro-da-ciencia-brasileira/. Acesso em: 02 nov. 2021.

Texto recebido em $03 / 11 / 2021$.

Texto aprovado em 09/11/2021. 